\title{
ORIGINAL ARTICLE \\ Sexual activity and sexual satisfaction in Korean men with spinal cord injury
}

\author{
Y-A Choi, J-H Kang and HI Shin
}

Study design: A cross-sectional survey.

Objectives: The aim of this study was to identify and assess the sexual activity and perceived sexual satisfaction of Korean males with spinal cord injury (SCl) and to identify factors influencing sexuality and satisfaction.

Setting: Community residents with $\mathrm{SCl}$.

Methods: A total of 139 male participants with SCl in Korea were eligible for inclusion in this study. All participants completed a faceto-face interview regarding sexuality and satisfaction, as well as structured questionnaires including items on socioeconomic factors, medical conditions and rehabilitation services.

Results: A total of 90 participants (65\%) were engaged in sexual activity. A period of 21-25 years since SCl (compared with the initial 5 years since $\mathrm{SCl}$ ) and an experience of direct sexual rehabilitation education were positively associated with sexual activity. Among 90 sexually active males with $\mathrm{SCl}, 8(8.9 \%)$ and $56(62.2 \%)$ were sexually satisfied and unsatisfied, respectively. Lower levels of education were strongly correlated with sexual dissatisfaction.

Conclusion: Korean males with $\mathrm{SCl}$ showed low levels of satisfaction regarding sexual activities. Results showed that socioeconomic factors (e.g., state of employment and direct person-to-person sexual counseling services) had a greater impact on sexual activity than the degree of physical impairment. Notably, the educational background was the most influential factor on sexual satisfaction.

Spinal Cord (2015) 53, 697-700; doi:10.1038/sc.2015.55; published online 31 March 2015

\section{INTRODUCTION}

Spinal cord injury (SCI) is a traumatic event for the affected individual because it often deteriorates the motor, sensory and autonomic functions. ${ }^{1}$ Moreover, SCI often eventually results in sexual impairment and can thus substantially affect the quality of life. ${ }^{2,3}$ However, despite this impact, the sexual activity of individuals with SCI has largely been neglected as a focus of research and is one of the most unmet needs for this group of individuals. ${ }^{4,5}$ In particular, although the sexual activity and coping strategies of people with SCI will likely be diverse across cultures because of cultural differences, ${ }^{6,7}$ little research has been published regarding the sexuality of individuals with SCI, particularly in East Asia. In one of the few studies addressing this issue for an Asian population, a comparative investigation of the life satisfaction between long-term survivors of SCI in Sweden and Japan found that the percentage of sexually active (SA) males engaged in sexual intercourse was significantly lower in Japan than in Sweden, and also observed an absence of sexual counseling for disabled people in the former country. ${ }^{8}$

Within the past 10 years, several hospitals and rehabilitation centers in Korea have offered sexual rehabilitation education and counseling programs for SCI patients. Nevertheless, the current situation regarding sexuality after SCI and the main factors for determining the sexual activity and sexual satisfaction of individuals remains unknown in Korea.

This study aimed to elucidate the sexual activity and perceived sexual satisfaction of Korean males with motor complete SCI and to identify the factors that influenced sexuality and satisfaction. These findings could be helpful for encouraging more fulfilled sexual lives among individuals with SCI in East Asia.

\section{MATERIALS AND METHODS}

\section{Participants}

All participants were members of the Korea Spinal Cord Injury Association (KSCIA). KSCIA is a non-profit, non-governmental organization for people with SCI, and its membership and participation are based on online websites. Of the 303 people with SCI who were active members of the KSCIA and willing to volunteer in the study, $246(81.2 \%)$ were male. Of these male subjects, 161 (66.2\%) had motor complete SCI. For this study, we analyzed only males with motor complete SCI.

\section{Survey}

The survey was conducted by the KSCIA through direct personal interviews with a self-reporting questionnaire. The participants were interviewed by two trained social workers at the KSCIA office. Participants were asked if they were using any sexual rehabilitation methods and to identify the type used if the answer was in the affirmative. These respondents were regarded as SA. The methods of sexual rehabilitation included orally administered medications such as sildenafil citrate (VIAGRA, Pfizer Manufacturing Australia Pty Limited, West Ryde, NSW, Australia), intravenous injection such as alprostadil (CAVERJECT IMPULSE, Pfizer Manufacturing Belguim NV, Rijksweg, Belguim), surgical treatment (e.g., prosthetic implants) and sex utensils. If the participants were not using any sexual rehabilitation techniques, they were regarded as sexually inactive (SI). The questions pertaining to sexual satisfaction were answered 
using a 5 -point Likert-type scale $(1=$ very satisfied, $2=$ satisfied, $3=$ neutral, $4=$ dissatisfied, $5=$ very dissatisfied). Socioeconomic variables included age, sex, marriage status, educational background, frequency of going out, current employment status and economic state. The medical condition included the type of paralysis, presence of medical complication and duration since the SCI, which was classified according to 5-year intervals. The source of information for sexual rehabilitation was divided into either direct or indirect sexual rehabilitation sources. Direct sources were considered to be from other people with SCI, social welfare services and rehabilitation doctors/specialists. Indirect sources were from mass media such as internet, television, guidance brochures, and so on.

\section{Statistical analysis}

The independent $t$-test for continuous variables and $\chi^{2}$ analyses for categorical variables were performed to identify differences in various demographic, socioeconomic and medical factors between the SA and SI groups. Additionally, binary logistic regression analysis for sexual activity and multiple logistic regression analysis for sexual satisfaction were performed to investigate important factors related to sexuality. $P$-values of $<0.05$ were considered significant. All statistical analyses were carried out with SPSS ver. 17.0 (SPSS Inc., Chicago, IL, USA).

\section{Statement of ethics}

We certify that all applicable institutional and governmental regulations concerning the ethical use of human volunteers were followed during the course of this research. The study procedures were reviewed and approved by our institution's research committee for human subjects [IRB No. 1409-032-608].

\section{RESULTS}

\section{Subject characteristics}

Of the 161 male subjects with motor complete SCI, 22 were excluded because of missing data with respect to age, partner status, the types of paralysis or the time since injury. Therefore, a total of 139 males were eligible for final inclusion in this study. The mean age was 43.3 years (range, 16-69 years), and the mean postinjury duration was $14.4 \pm 7.7$ years (range, 1-40 years; median, 14 years). Of the study population, $64(46 \%)$ and $75(53.9 \%)$ were with partners and without partners, respectively. Moreover, 27 (19.4\%) and $112(80.6 \%)$ had complete tetraplegia and complete paraplegia, respectively. Additionally, 56 participants $(40.3 \%)$ were in paid employment, and $50(36 \%)$ had a university or advanced degree.

\section{Sexual activity}

A total of 90 participants (65\%) were engaged in sexual activity. Of these, $60(67 \%)$ and $25(28 \%)$ participants were taking orally administered medications and using intravenous injections of alprostadil, respectively. Meanwhile, $2(2 \%)$ maintained their sexual life with the aid of sex utensils, and 3 (3\%) had undergone surgical treatment (e.g., prosthetic implants).

Both the employment rate and percentage of subjects with an experience of direct sexual rehabilitation education regarding sexual activity were significantly greater in the SA group than those in the SI group ( $P=0.038$ and $P=0.011$, respectively). A significant difference in the time since the injury was also observed between the SA and SI groups $(P=0.003)$ (Table 1$)$. The binary logistic regression analysis revealed a period of 21-25 years since SCI (compared with the initial 5 years since $\mathrm{SCI}$ ) and an experience of direct sexual rehabilitation education were independent factors strongly correlated with sexual activity (odds ratio, 3.33) (Table 2).

\section{Sexual satisfaction among SA males}

Based on the Likert-type scores, none of 90 SA males were very satisfied. Instead, 8 participants $(8.9 \%)$ were satisfied, whereas 26 (28.9\%) were neither satisfied nor unsatisfied. Furthermore, 28 participants $(31.1 \%)$ were dissatisfied, whereas another $28(31.1 \%)$ were very dissatisfied. To assess further the factors associated with sexual satisfaction among the SA group, we classified these subjects into three groups with reference to the Likert-type scale: Group A (scores of 1 and 2); Group B (score of 3); and Group C (scores of 4 and 5) (Table 3). Based on the analysis using this classification system, a lower level of background education was found to be significantly

Table 1 Comparison between the sexually active group and the sexually inactive group in males with motor complete $\mathrm{SCl}$

\begin{tabular}{|c|c|c|c|c|c|}
\hline \multirow[t]{2}{*}{ Characteristics } & \multicolumn{2}{|c|}{$\begin{array}{l}\text { Sexually active } \\
\text { group }(\mathrm{n}=90)\end{array}$} & \multicolumn{2}{|c|}{$\begin{array}{l}\text { Sexually inactive } \\
\text { group }(\mathrm{n}=49)\end{array}$} & \multirow[t]{2}{*}{ P-value } \\
\hline & $n$ & $\%$ & $\mathrm{n}$ & $\%$ & \\
\hline Age (mean) & \multicolumn{2}{|c|}{$\begin{array}{c}42.8 \pm 9.9 \\
(16-69)\end{array}$} & \multicolumn{2}{|c|}{$\begin{array}{c}44.2 \pm 11 \\
(25-63)\end{array}$} & 0.47 \\
\hline Partner status & & & & & 0.88 \\
\hline With partner & 41 & 45.6 & 23 & 46.9 & \\
\hline Without partner & 49 & 54.4 & 26 & 53.1 & \\
\hline Level of education & & & & & 0.55 \\
\hline$\leqslant$ High school & 56 & 62.2 & 33 & 67.3 & \\
\hline$>$ College & 34 & 37.8 & 16 & 32.7 & \\
\hline Employment status & & & & & $0.04^{*}$ \\
\hline Full or part time & 42 & 46.7 & 14 & 28.6 & \\
\hline None & 48 & 55.3 & 35 & 71.4 & \\
\hline Economic status & & & & & 0.21 \\
\hline Non-recipients & 56 & 62.9 & 25 & 52.1 & \\
\hline $\begin{array}{l}\text { Recipients of pension under Basic } \\
\text { Living Assurance Law or under the } \\
\text { lower income group }\end{array}$ & 33 & 37.1 & 23 & 47.9 & \\
\hline Frequency of going out & & & & & 0.05 \\
\hline Daily outing & 62 & 69.7 & 26 & 53.1 & \\
\hline No or occasional outing & 27 & 30.3 & 23 & 46.9 & \\
\hline Type of paralysis & & & & & 0.50 \\
\hline Complete tetraplegia & 19 & 21.2 & 8 & 16.3 & \\
\hline Complete paraplegia & 71 & 78.9 & 41 & 83.7 & \\
\hline Time since injury (years) & & & & & $0.003 *$ \\
\hline $1-5$ & 10 & 11.1 & 3 & 6.1 & \\
\hline $6-10$ & 19 & 21.1 & 16 & 32.7 & \\
\hline $11-15$ & 31 & 34.4 & 5 & 10.2 & \\
\hline $16-20$ & 17 & 18.9 & 10 & 20.4 & \\
\hline $21-25$ & 5 & 5.6 & 11 & 22.4 & \\
\hline $25-30$ & 3 & 3.3 & 4 & 8.2 & \\
\hline $31-35$ & 4 & 4.4 & 0 & 0 & \\
\hline $35-40$ & 1 & 1.1 & 0 & 0 & \\
\hline Education regarding sexual activity & & & & & $0.01^{*}$ \\
\hline Direct & 67 & 82.7 & 24 & 61.5 & \\
\hline Indirect & 14 & 17.3 & 15 & 38.5 & \\
\hline
\end{tabular}

Abbreviation: $\mathrm{SCl}$, spinal cord injury. ${ }^{*} P<0.05$. 
Table 2 Binary logistic regression model for sexual activity

\begin{tabular}{lccc}
\hline Characteristics & Odds ratio & $95 \% \mathrm{Cl}$ & P-value \\
\hline Time since injury (years) & & & \\
$\quad 1-5$ & 1 & - & - \\
$6-10$ & 3.79 & $0.71-20.14$ & 0.12 \\
$11-15$ & 0.73 & $0.12-4.39$ & 0.73 \\
$16-20$ & 2.65 & $0.47-14.78$ & 0.27 \\
$21-25$ & 9.9 & $1.54-63.69$ & $0.02^{*}$ \\
$25-30$ & 6.0 & $0.70-51.10$ & 0.10 \\
$31-35$ & 0 & - & 0.99 \\
$35-40$ & 0 & - & 1.00 \\
& & & \\
Education regarding sexual activity & 1 & - & - \\
Indirect & 3.33 & $1.31-8.41$ & $0.01^{*}$ \\
$\quad$ Direct & & & \\
Employment status & 1 & - & - \\
$\quad$ None & 1.45 & $0.60-3.51$ & 0.41 \\
Full or part time & & & \\
Frequency of going out & & & - \\
$\quad$ No or occasional outing & 1 & & \\
Daily outing & 1.72 & $0.72-4.1$ & 0.22 \\
\hline
\end{tabular}

Abbreviation: $\mathrm{Cl}$, confidence intervals.

${ }^{*} P<0.05$.

associated with sexual dissatisfaction $(P=0.021)$ (Table 3). Furthermore, the impact of direct sexual rehabilitation education was only of slight significance $(P=0.06)$. The multiple logistic regression analysis indicated that compared with Group A, a lower level of education was the most influential factor for sexual dissatisfaction in Group B (odds ratio, 6.74) (Table 4).

\section{DISCUSSION}

Limited research has been published on the sexuality of Asian women with SCI, such as in Malaysia or Turkey. ${ }^{6,7}$ However, to our knowledge, no previous formal academic study has described the overall current state of sexuality and sexual satisfaction among Asian men with motor complete SCI.

In the present study, $62.7 \%$ of the participants were SA. The subjects in this group were more likely to be employed, have a longer period of time since the injury and have direct educational information for sexual rehabilitation than those not SA. These findings on the percentage of SA males with SCI in Korea are comparable or somewhat lower compared with those reported for other recent studies. Sösteen et al. ${ }^{9}$ and Reitz et al. ${ }^{10}$ reported 64\% (60 males) and $60 \%$ (47 males) with SCI had had intercourse, respectively. Additionally, Dahlberg et al. ${ }^{11}$ reported that $68 \%$ of 92 males with traumatic SCI had engaged in sexual activity.

Furthermore, when compared with the sexual activity of healthy middle-aged males in the population throughout both the East and West, ${ }^{12,13}$ the sexual activity of males with SCI was definitely reduced. In general, people with physical disabilities are known to have more limited sexual lives. ${ }^{14}$

The sexual satisfaction of SA Korean men in this study was relatively lower than that of other reports in Western countries. The research of Dahlberg et al. ${ }^{11}$ reported that $36 \%(n=33)$ of their study subjects were very or somewhat satisfied with their sexual life. Berkman et al. ${ }^{15}$ assessed the sex lives of 104 male SCI veterans and found that $41 \%, 36 \%$ and $23 \%$ had satisfactory, somewhat satisfactory and
Table 3 Comparison of sexually active groups for sexual satisfaction

\begin{tabular}{|c|c|c|c|c|c|c|c|}
\hline \multirow[t]{2}{*}{ Characteristics } & \multicolumn{2}{|c|}{$A(\mathrm{n}=8)$} & \multicolumn{2}{|c|}{$B(\mathrm{n}=26)$} & \multicolumn{2}{|c|}{$C(\mathrm{n}=56)$} & \multirow[t]{2}{*}{ P-value } \\
\hline & $\mathrm{n}$ & $\%$ & $n$ & $\%$ & $n$ & $\%$ & \\
\hline Age & \multicolumn{2}{|c|}{$37.1 \pm 13.5$} & \multicolumn{2}{|c|}{$42.8 \pm 8.4$} & \multicolumn{2}{|c|}{$43.7 \pm 9.6$} & 0.21 \\
\hline Partner status & & & & & & & 0.96 \\
\hline With partner & 4 & 50 & 12 & 46.2 & 25 & 44.6 & \\
\hline Without partner & 4 & 50 & 14 & 53.8 & 31 & 55.4 & \\
\hline Level of education & & & & & & & $0.02^{*}$ \\
\hline$\leqslant$ High school & 3 & 37.5 & 21 & 80.8 & 32 & 57.1 & \\
\hline$>$ College & 5 & 62.5 & 5 & 19.2 & 24 & 42.9 & \\
\hline Employment status & & & & & & & 0.06 \\
\hline Full or part time & 7 & 87.5 & 11 & 42.3 & 24 & 42.9 & \\
\hline None & 1 & 12.5 & 15 & 57.7 & 32 & 57.1 & \\
\hline Economic status & & & & & & & 0.48 \\
\hline Non-recipient & 6 & 75 & 18 & 69.2 & 32 & 58.2 & \\
\hline Recipients ${ }^{a}$ & 2 & 25 & 8 & 30.8 & 23 & 41.8 & \\
\hline Frequency of going out & & & & & & & 0.49 \\
\hline Daily outing & 7 & 87.5 & 17 & 65.4 & 38 & 69.1 & \\
\hline No or occasional outing & 1 & 12.5 & 9 & 34.6 & 17 & 30.9 & \\
\hline Level of $\mathrm{SCl}$ & & & & & & & 0.41 \\
\hline Complete tetraplegia & 3 & 37.5 & 4 & 15.4 & 12 & 21.4 & \\
\hline Complete paraplegia & 5 & 62.5 & 22 & 84.6 & 44 & 78.6 & \\
\hline
\end{tabular}

Time since injury (years)
$1-5$
$6-10$
$11-15$
$16-20$
$21-25$
$25-30$
$31-35$
$35-40$

Education regarding sexual

activity

$\begin{array}{lcccccc}\text { Direct } & 4 & 50 & 19 & 86.4 & 44 & 86.3 \\ \text { Indirect } & 4 & 50 & 3 & 13.6 & 7 & 13.7\end{array}$

Abbreviations: $\mathrm{SCl}$, spinal cord injury.

A, Sexually satisfied group; B, sexually neither satisfied nor dissatisfied group; C, sexually dissatisfied group.

${ }^{*} P<0.05$.

aPension under Basic Living Assurance Law or under the lower income group.

Table 4 Multiple logistic regression model for sexual satisfaction

\begin{tabular}{cccc}
\hline Characteristic & Odds ratio & $95 \% \mathrm{Cl}$ & P-value \\
\hline $\begin{array}{l}\text { Level of education } \\
\text { S High school }\end{array}$ & & & \\
A & 1 & - & - \\
B & 6.74 & $1.13-40.34$ & $0.04^{*}$ \\
C & 2.22 & $0.44-11.12$ & 0.33 \\
$>$ College & 1 & - & - \\
\hline
\end{tabular}

Abbreviation: $\mathrm{Cl}$, confidence intervals.

A, Sexually satisfied group; B, sexually neither satisfied nor dissatisfied group; C, sexually dissatisfied group.

${ }^{*} P<0.05$. 
unsatisfactory sex lives, respectively. The predominant Confucian cultural influences on sexual attitudes may explain the lower sexual satisfaction of males with SCI in the present study than that of participants in Western studies. ${ }^{12}$ For example, life satisfaction in persons with SCI between Japan and Sweden was investigated in the context of cultural differences between East Asian and North European cultures. The Japanese SCI patients more often responded that they were sexually dissatisfied than Swedish SCI patients. ${ }^{8}$ Faceto-face interviews were chosen over letters or mail-back questionnaires because indirect questioning could have resulted in lower response rates and lack of validity because of cultural influence.

However, even within the present cultural context of the study population, we found that lower educational attainment and direct sexual rehabilitation education (although it was only slightly significant) had a great impact on sexual satisfaction. Education and counseling for sexuality are often poorly incorporated into the rehabilitation process. ${ }^{16,17}$ Therefore, based on the present findings, rehabilitation physicians and faculties need to integrate person-toperson tailored sexual education and sexual counseling services as part of a comprehensive rehabilitation program, in consideration of the individuals' academic background.

In the present study, we observed the severity of SCI (paraplegia or tetraplegia) was not associated with sexuality, which is consistent with the findings of previous research. In particular, Siösteen et al. found that physical and social independence and high mood levels were positive determinants of sexual adaptation after the injury, whereas the neurological level and completeness of the injury were not significantly correlated with sexuality. ${ }^{9}$ Moreover, Kreuter et al. ${ }^{18}$ reported that psychosocial rather than physical factors are more essential for a satisfactory sex life and relationships within this population. Hence, the current findings support previous results that sexual adjustment after SCI depends on factors other than the degree of physical disability.

This study had several limitations. First, because of an inhibited attitude toward sexuality in Asia, including Korea, ${ }^{12,19}$ we were unable to ask direct questions with respect to the presence of sexual activity, sexual partnership status and frequency of intercourse or sexual orgasm in the preliminary questionnaire of the survey. Second, previous studies have reported that psychological factors such as depression, intimacy with a partner and self-esteem are closely related to sexual satisfaction; however, we were unable to deal with psychological or emotional aspects in the present study. Finally, sexuality constitutes a fundamental part of people's lives, integrating physical, emotional, intellectual and social aspects. ${ }^{20}$ Multimodal assessments for sexuality should be considered for further investigation.

Although this study had the above-mentioned limitations, these findings provide useful information for the current sexual rehabilitation intervention of patients with SCI and supporting data for developing the contents of both short- and long-term rehabilitation education programs in the future.

\section{DATA ARCHIVING}

There were no data to deposit.

\section{CONFLICT OF INTEREST}

The authors declare no conflict of interest.

\section{ACKNOWLEDGEMENTS}

We are thankful to the Korea Spinal Cord Injury Association (KSCIA).

1 Ackery A, Tator C, Krassioukov A. A global perspective on spinal cord injur epidemiology. J Neurotrauma 2004; 21: 1355-1370.

2 Lindner $\mathrm{H}$. Perceptual sensitization to sexual phenomena in the chronic physically handicapped. J Clin Psychol 1953; 9: 67-68.

3 Anderson KD. Targeting recovery: priorities of the spinal cord-injured population. J Neurotrauma 2004; 21: 1371-1383.

4 Kennedy P, Lude P, Taylor N. Quality of life, social participation, appraisals and coping post spinal cord injury: a review of four community samples. Spinal Cord 2006; 44: 95-105.

5 Alexander CJ, Sipski ML, Findley TW. Sexual activities, desire, and satisfaction in males pre- and post-spinal cord injury. Arch Sex Behav 1993; 22: 217-228.

6 Julia PE, Othman AS. Barriers to sexual activity: counselling spinal cord injured women in Malaysia. Spinal Cord 2011; 49: 791-774.

7 Celik EC, Akman Y, Kose P, Arioglu P, Karatas M, Erhan B. Sexual problems of women with spinal cord injury in Turkey. Spinal Cord 2014; 52: 313-315.

8 Ide M, Fugl-Meyer AR. Life satisfaction in persons with spinal cord injury: a comparative investigation between Sweden and Japan. Spinal Cord 2001; 39: 387-393.

9 Siösteen A, Lundqvist C, Blomstrand C, Sullivan L, Sullivan M. Sexual ability, activity, attitudes and satisfaction as part of adjustment in spinal cord-injured subjects. Paraplegia 1990; 28: 285-295.

10 Reitz A, Tobe V, Knapp PA, Schurch B. Impact of spinal cord injury on sexual health and quality of life. Int J Impot Res 2004; 16: 167-174.

11 Dahlberg A, Alaranta HT, Kautiainen H, Kotila M. Sexual activity and satisfaction in men with traumatic spinal cord lesion. J Rehabil Med 2007; 39: 152-155.

12 Moreira ED Jr, Kim SC, Glasser D, Gingell C. Sexual activity, prevalence of sexual problems, and associated help-seeking patterns in men and women aged 40-80 years in Korea: data from the Global Study of Sexual Attitudes and Behaviors (GSSAB). J Sex Med 2006; 3: 201-211.

13 Corona G, Lee DM, Forti G, O'Connor DB, Maggi M, O'Neill TW, et al. Age-related changes in general and sexual health in middle-aged and older men: results from the European Male Ageing Study (EMAS). J Sex Med 2010; 7: 1362-1380.

14 McCabe MP, Taleporos G. Sexual esteem, sexual satisfaction, and sexual behavior among people with physical disability. Arch Sex Behav 2003; 32: 359-369.

15 Berkman AH, Weissman R, Frielich MH. Sexual adjustment of spinal cord injured veterans living in the community. Arch Phys Med Rehabil 1978; 59: 29-33.

16 Tepper MS. Sexual education in spinal cord injury rehabilitation: current trends and recommendations. Sex Disabil 1992; 10: 15-31.

17 McAlonan S. Improving sexual rehabilitation services: the patient's perspective. Am J Occup Ther 1996; 50: 826-834.

18 Kreuter M, Sullivan M, Siösteen A. Sexual adjustment after spinal cord injurycomparison of partner experiences in pre- and postinjury relationships. Paraplegia 1994; 32: 759-770.

19 Nicolosi A, Glasser DB, Kim SC, Marumo K, Laumann EO. GSSAB Investigators' Group. Sexual behaviour and dysfunction and help-seeking patterns in adults aged 40-80 years in the urban population of Asian countries. BJU Int 2005; 95: 609-614.

20 Ferreiro-Velasco ME, Barca-Buyo A, de la Barrera SS, Montoto-Marqués A, Vázquez XM, Rodríguez-Sotillo A. Sexual issues in a sample of women with spinal cord injury. Spinal Cord 2005; 43: 51-55. 